\title{
Doubling Time and Population Increase of the Amish
}

Joseph F. Donnermeyer

Professor Emeritus

School of Environment and Natural Resources

The Ohio State University

Columbus, Ohio 43210

\begin{abstract}
Current estimates of Amish population growth often cite a "doubling time” figure, but fail to substantiate the source from which the estimate was derived. As well, some estimates of population increase, such as by the Young Center for Anabaptist and Pietist Studies at Elizabethtown College, use net change in the number of church districts as a proxy to determine population change, rather than a more precise counting up of children and adults. Unfortunately, a direct "head count" of the Amish, and changes in this count overtime to create a doubling time estimate, would be very daunting, Until there is a valid database from which this can be accomplished, an alternative is to calculate doubling time based on net change in the number of households in various Amish settlements from one year to the next. In this article, end-of-year statistics submitted by scribes from hundreds of Amish settlements to a monthly periodical known as The Diary are used to estimate doubling time. Five time periods, each representing consecutive years from 2009 through 2014 for which the number of households for the same settlement is reported, are used to create a doubling time estimate. Altogether, there were 673 data-points for which consecutive year information about the same settlement was available. The article discusses possible limitations to using The Diary and households to calculate a doubling time, as well as the possible uses of an accurate doubling time estimate for research and application.
\end{abstract}

\section{Keywords}

Doubling time; Migration; Population increase; The Diary; Young Center for Anabaptist and Pietist Studies; 


\section{Introduction}

Inarguably, the most important demographic feature of the Amish over the past half century is population increase. ${ }^{1}$ The social forces that drive this increase are large families, a high rate of retention through baptism of daughters and sons into the Amish faith as they reach the age of decision, and little attrition or switching to non-Amish church groups among baptized adults (Donnermeyer, Anderson and Cooksey 2013; Ericksen, Ericksen, Hostetler and Huntington 1979; Greska and Corbin 2002; Meyers 1994).

The purpose of this article is to report on the time it takes the Amish population to double in size, or "doubling time" (Weinstein and Pillai 2001), and how doubling time was calculated. Doubling time itself is a concept used in a wide variety of disciplines concerned with population change, ranging from medical specialists who need to know how rapidly a parasite can spread, to the field of finance where it is used to calculate the growth of money accounts based on various rates of compounded interest, to sociologists who examine the relationship of population change to social change, development, and the quality of life of peoples and societies around the world. Doubling time allows those who systematically and empirically study population dynamics- the science of demography - to conduct comparative research of population change in different societies and subcultures or of the same populations over various historical periods.

\section{The Significance of Population Change and Amish Society}

The most direct consequence of population increase is the growth in the number of Amish settlements, and their spread to regions of Canada and the United States where, historically, there has been little or no Amish presence in the past (Anderson and Donnermeyer 2013;

Donnermeyer and Cooksey 2010; Donnermeyer and Luthy 2013). Closely related is the frequent migration of Amish families and individuals. Recently established settlements fill up with new families from other places, new ministers are ordained, and a sustainable community is created. As Meyers and Nolt (2005) observed: “The Amish have always been a people on the move” (23).

Johnson-Weiner's (2010) documentation of rapid settlement expansion, coupled with the diversity of Amish affiliations that have moved into the state of New York, illustrate how quickly a state can feel an Amish presence in its rural regions. Appendix B of her book contains a list of 27 Old Order Amish communities founded and still existing within the Empire State as of 2007. ${ }^{2}$ Only 14 were extant before 2000, meaning an average of nearly two new settlements were founded every year during the first seven years of the twenty-first century. However, if her book was re-issued today, another 24 new settlements (three new settlements per year) would have to be added to the list (Luthy and Donnermeyer 2014). New York now ranks third in the number of settlements—slightly behind Ohio and Pennsylvania—and if current trends continue, could soon occupy the top position for the most settlements of any state or province.

But, the effects do not stop at geographic expansion and migration. Hostetler $(1993,370)$ 
cites establishment of new settlements as a way to maintain strong family and church bonds. This same theme forms part of Stevick's (2014, 17-19) thesis about the differences between older and larger "peer-centered" settlements versus newer and smaller "adult-centered" settlements in terms of how well they perform the vital community functions of socialization and social control (Warren 1963; Liepens 2000) of young people, which in turn influences how the Amish way of life is reproduced from one generation to the next.

Population increase is believed by Hurst and McConnell (2010) to be a key internal dynamic to the growing diversity of Amish church discipline or Ordnung and the diversity of interpretations by which the principle of separation from the world and related social practices are applied. It is also cited as a prime reason for the shift out of agriculture and into nonagricultural occupations held by Amish men to support their families because the ability to find affordable farmland cannot keep pace with population gains (Kraybill, Johnson-Weiner and Nolt 2013; Kreps, Donnermeyer and Kreps 1994). Sawmills, furniture-making, and other non-farm occupations do not require the same amount of land, but still retain characteristics desired by the Amish, which is a rural-located lifestyle and either home-based businesses or work which does not take the breadwinner too far away from the family, both by distance and length of time.

\section{Prior Doubling Time Estimates}

Hostetler $(1993,102)$ claims a doubling time of 23 years, but this number appears to be derived from only the Greater Holmes County, Ohio settlement. Other estimates are bandied about; however, the documentation is weak. For example, Donnermeyer and Cooksey (2010), and Kraybill, Johnson-Weiner and Nolt (2013) cite a doubling time of 20 years, but fail to provide an adequate explanation for how this statistic was empirically established, or to cite a peer-reviewed source for their information. As well, Donnermeyer, Anderson, and Cooksey's (2013) article on the Amish population across counties of the U.S and equivalent governmental units in Canada mentions a doubling time of 21.25 years, but again, without a clear explanation of its source.

The Young Center for Anabaptist and Pietist Studies (2014) claims an annual (and presumably constant) growth rate of 3 percent, which translates to a doubling time of about 23.45 years, a figure close to Hostetler's (1993) assertion. However, their proclamation is based ultimately on counting up the number of church districts from one year to the next. This is problematic for two reasons. First, it provides only a rough benchmark of population change because the size of a church group can vary greatly. Second, a division from one church group to two is certainly an indicator of growth, but does not mean a doubling of the Amish population within those church districts. It may take many years for each church group to grow to the same size, respectively, as the church district from which they originated. Although this may be a trivial concern for estimating the population of the largest Amish communities with dozens and perhaps hundreds of church districts, it is quite significant for gauging the population size for the vast majority of settlements, which are smaller and contain only a few church districts. Church 
district as a proxy for population size of settlements (or, even when aggregated to a state level estimate) can result in frequent and significant errors and is at best a type of quasi-scientific guessing game.

Beside reliance on a unit of analysis as large as a church district, another shortcoming of prior doubling time estimates is the number and size of localities included in the calculation. This is a question of the representativeness of the settlements from which the estimate is established. However, it is difficult to be more specific in acknowledging this shortcoming because the current doubling time assertions fail to provide sufficient documentation about the places where their statistical data are derived, with the exception of Hostetler (1993). In the end, we are left with the impression that the doubling time figure is a claim loosely made. Regardless, relying on population change in a few large settlements, large and small, or even a range of settlements by size within a single state or limited number of states, may affect the accuracy of any doubling time estimate.

It could be argued that the calculation of doubling time that provides a more precise numerical value of population change for estimating the future size of the Amish population is not important when compared to larger social, economic, religious, and cultural changes within Amish society itself. However, a figure more solidly based on the methods of demography better informs all Amish and Anabaptist scholars, regardless of their specific interests. In addition, the media often cite shaky claims when featuring a story about the Amish, which contributes to the biased and/or inaccurate nature of news stories and numerous Amish reality shows, which are neither real nor accurate (Zimmerman Umble and Werner-Zercher 2008). ${ }^{3}$

As well, what may seem like a small difference between doubling times of 20 and 23 years, for example, is very significant for understanding population change and how it ripples through the fabric of Amish society and culture. As a hypothetical consideration, let's assume a population of 100 and a doubling time of 20 years. This represents an annual percentage increase of 3.529. Assuming this is a constant rate of annual growth, within 5 years, the population would have surged to 119, rounded to a whole number. Consider now a doubling time of 23 years on the same base population of 100 persons. This is an annual percentage increase of 3.059 years. Five years later, the population would have grown to 116 persons, again, rounded to a whole number. ${ }^{4}$ There is now a divergence of 2.6 percent, which grows ever larger in volume and more significant both for its consequences if the base on which the estimate is made is not 3 digits (hundreds) but 6 digits (hundred thousands), and for each additional year into the future a projection is made.

\section{Research Question}

What is missing from the conversation about Amish population increase and settlement expansion, and their implications for religious, cultural, economic and social change, is an actual calculation for how quickly the population is growing. This article presents one way of 
developing a doubling time estimate of the Amish population and the way those procedures provide a basis on which the estimate can be updated on an annual basis.

\section{Methodology}

Population growth is dependent on two specific factors, namely, natural increase/decrease and net migration (Bogue 1969). The former is simply the number of births minus the number of deaths in a population, while the latter is the number of people who move or migrate in minus the number of people who move or migrate out. In the case of any over-all estimate of the Amish population across all the nearly 500 settlements in existence today (Donnermeyer and Luthy 2013), out-migration is represented by the percentage or rate of Amish who leave the faith. Past research has already established that attrition among baptized members is low and the retention of offspring who decide to be baptized Amish upon reaching early adulthood has risen greatly (Greska and Corbin 2002; Hurst and McConnell 2010, 79-80; Meyers 1994).

Ideally, doubling time should be determined by a "head count" of a population from one point in time to the next. That is not always possible, so, alternative measures are often used. For example, Kraybill, Johnson-Weiner, and Nolt (2013) use church district as a proxy for fluctuations in the Amish population. This is the same proxy measure used by the Young Center for their population estimates.

A more precise and improved method might be to use the directories published for various settlements, which list all members residing in a single household. Even though some of these directories, such as the recently published 2015 edition of the Holmes County and Vicinity Directory (Wengerd 2015), are an excellent source of demographic data, similar directories for a wide range of settlements within the exact same period of time are not available. Hence, even though directories may appear to be a much better source of data than mere counts of church districts, calculating a doubling time for the total Amish population in all of the settlements of North America from directory information creates different problems. Times of directory publication vary, and for many settlements, there is no published directory.

An alternative that avoids the problem created by using large, aggregated units like the church district or attempting to coordinate an estimate from the variable publication dates of directories is to count up the number of households across settlements for the same time period with the assumption that average household size does not change or changes very little in the short-term (Ericksen, et al., 1980; Hostetler 1993; Kraybill, Johnson-Weiner, and Nolt 2013; Wasao and Donnermeyer 1996). The household unit is not as ideal as an actual count of all adults and children but far superior to using the church district as a proxy for population size.

The Diary is a monthly periodical for "Old Order Churches," published in Bart, Pennsylvania. Several hundred reports of news about the weather, births, deaths, marriages, visiting and other events from settlements throughout Canada and the United States are published in each issue. The reporters or scribes in the various settlements collect the news and 
then send the information in the form of a narrative to the editor, where it is put in typeset and published for its readers.

In the January and February issues of The Diary, many of the scribes report end-of-year "statistics." 5 Typically, these statistics include such information for the previous year as the number of births, deaths, families moving in, families moving out, schools, school aged children, and church districts. Many also include information on the number of households in the settlement. ${ }^{6}$

Information about the number of households in a settlement provides the means to calculate a more scientifically established and statistically precise doubling time number. Even though the use of households may seem less accurate than a calculation based on counts of individuals at two different points in time, Amish migration is household-based and Amish family size has not varied much over the decades (Greska and Corbin 2002; Kraybill, JohnsonWeiner, and Nolt 2013; Wasao and Donnermeyer 1996).

The statistics reports in the The Diary are annual, therefore, it is possible to assemble a large number of household counts for settlements where scribes are diligent in reporting the vital numbers in consecutive years. Data for this article was collected from the appropriate editions of The Diary for six consecutive years-2010 through 2015. To make clear, the statistics are for the previous year, hence, the data reflects counts on the number of households for the years 2009 through 2014.

Nearly 300 settlements of all sizes and regions of Canada and the United States provided statistics on the number of households for two or more consecutive years during this time period. ${ }^{7}$ However, not every settlement reported year-end statistics for each of the study years. Because of this, it was necessary to build a set of data-points for each settlement in which a scribe reported the number of households for two consecutive years only. For example, the number of households was disclosed in both 2009 and 2010 for the same 131 settlements, providing 131 data-points for calculating percentage change in the population (Table 1). For 2010 and 2011, consecutive year household counts for the same 122 settlements were reported by scribes. Altogether, over the five paired sets of consecutive years, 673 data-points for this article were collected.

The appropriate doubling time formula depends on the nature of the object or population under study. One advantage of using consecutive year statistics from The Diary is that the assumption of a constant rate of increase is automatically met. As well, with five sets of consecutive year data-points, any change in the rate of Amish population growth, whether minor or major, from one set of consecutive years to the next, can be averaged with other years to produce a weighted and hence more stable estimate.

Assuming a constant rate or percentage of change, a formal expression of the doubling time formula is: $\mathrm{T}_{\mathrm{d}}=\left(\mathrm{t}_{2} \_\mathrm{t}_{1}\right) * \log (2) / \log \left(\mathrm{q}_{2} / \mathrm{q}_{1}\right)$. $\mathrm{T}_{\mathrm{d}}$ is the doubling time, while $\mathrm{q}_{2}$ and $\mathrm{q}_{1}$ are the 
quantities at time 2 and time 1, respectively. In this case, the quantities are the number of households. The other part of the formula can be ignored because the data-points are based on a one year interval, that is, $t_{2}$ minus $t_{1}$ is 1 . Hence, doubling time is the logarithmic value for the number 2 (or doubling), divided by the logarithmic value for the value derived from the number of households at time 2 divided by the number of households at time 1 .

A less formal expression, and easy to calculate, even for those who long ago forgot what they learned in their high school algebra and calculus courses, is the "rule of 70" (Weinstein and Pillai 2001). The actual amount of time it takes for a population with a constant rate of growth to double can be expressed by the number .0693147, the natural log value of 2 , divided by the rate of change. For convenience of calculation, such as to estimate savings account growth based on compounded interest, the number 70 is divided by the percentage change in a population (or the number 7 is used if the change is expressed in decimal form). Hence, if the change in the number of households from 2009 to 2010 is +3.3297 , then the doubling time is 21.039 years.

\section{Results}

At least one settlement from 27 states and the province of Ontario reported consecutive statistics on the number of households in their communities. Only three states are not found in this analysis, and in all three, there is only one settlement. The first is Delaware, with its only settlement (ten church districts) of Dover. The other two are North Carolina, with the settlement of Union Grove (one church district), and Idaho, with the recently (2012) established settlement of Salmon (one church district) (Raber 2014).

The number of households in a settlement for which consecutive year reports were available ranged from as few as five (Palestine, WV) to nearly 1,000 (Smicksburg, PA). Altogether, reports from 39 (13.2\%) settlements contained more than 100 households, whereas 16 (5.4\%) included less than 10 households, and 138 (46.6\%) scribes said their settlement had 11 to 29 households. The vast share of the settlements with fewer than 30 households was also settlements with a single church district. Finally, another 103 (34.8\%) indicated 30 to 99 households. This distribution is based on the number of households for the earliest year the information was available for a settlement.

The doubling time is based on all settlements with consecutive year statistics for households, whether or not the number increased, stayed the same, or decreased. In general, for the five sets of consecutive years, about two-thirds of the communities experienced an increase in the number of households (Table 1). The remainder experienced no change or saw a decrease in the number of households for their settlements. The increases are due to either the establishment of new households through marriage and/or net gain from in-migration, while the settlements experiencing no change had no migration, either in or out, or a net balance of zero based on an even exchange of households migrating in and out. Settlements displaying a decrease in population most likely reflect net out-migration, perhaps due to lack of land to 


\section{Table 1: Percentage Increase in Number of Households for Consecutive Years and Doubling Time}

\begin{tabular}{l|ccccc} 
& $2009-10$ & $2010-11$ & $2011-12$ & $2012-13$ & $2013-14$ \\
\hline Settlements (i.e., data points) & 131 & 122 & 138 & 141 & 141 \\
\hline Household change for & & & & & \\
consecutive years & & & & & \\
$\quad$ Percent—more households & 67.2 & 63.1 & 69.5 & 64.5 & 63.2 \\
$\quad$ Percent-no change & 12.2 & 13.1 & 8.0 & 15.6 & 19.1 \\
$\quad$ Percent—fewer households & 20.6 & 23.8 & 22.5 & 19.9 & 17.7 \\
\hline Total number of households & & & & & \\
Time 1 (q1) & 7,122 & 7,050 & 8,082 & 8,938 & 9,161 \\
$\quad$ Time 2 (q2) & 7,359 & 7,249 & 8,400 & 9,264 & 9,489 \\
\hline Percentage change & +3.3277 & +2.8227 & +3.9347 & +3.6473 & +3.5804 \\
Doubling time (years) & 21.17 & 24.90 & 17.96 & 19.35 & 19.70
\end{tabular}

Doubling time (weighted average) $=20.4987$

expand or a disagreement over the Ordnung (Luthy 2011). As well, these settlements may be experiencing a net decrease because no new households were formed through marriage and some households may have been lost through death, with survivors moving in with other families in the same settlements or other settlements where extended family members are located. As well, defecting households (those which decide to join non-Amish churches) may not move, but would no longer be counted in the statistics reports of scribes.

The total number of households for any two consecutive years serves as the q1 and q2, respectively, in the doubling time formula. As seen in Table 1, the percentage change in the total number of households in the five sets of consecutive years ranges from $+2.8 \%$ (2010 to 2011) to $+3.9 \%$ (2011 to 2012). The total number of households varies for the same year from one set of consecutive years to another because the settlements from which end-of-year statistics are reported for two years in a row vary. Even though there were a substantial number of communities (63) for which statistics are available for all six years used in the analysis, end-ofyear statistics reporting is less consistent for many other settlements. A decision was made to retain the more rigorous standard that there must be consecutive year reports submitted by the scribes to The Diary, rather than assume a constant rate of change as a proxy measure for the missing data across non-consecutive years for settlements where reports were less regular.

The proportion of data-points included in each consecutive year to the total number of data-points was used to create a weighted doubling time average. The weighted doubling time was calculated at 20.4987 years, or more practically, 20.5 years. This is a slower rate of increase than the unsubstantiated "20 year” figure used by both Donnermeyer and Cooksey (2010) and Kraybill, Johnson-Weiner, and Nolt (2013), but faster than Hostetler's (1993) assumption of 23 years, and the current 23.4 year doubling time which can be derived from the Young Center web 
page claim about population increase. In reference to Hostetler's (1993) estimate of 23 years, perhaps the difference is due to increases in retention or baptism rates between the time when he arrived at this figure and more recent times, which in turn, results in more households, more settlements, and more growth within most settlements. However, it could also be due to his reliance of only one, albeit, large settlement.

Variations in the total number of households clearly show the advantage of creating a weighted average for doubling time because using only a single set of consecutive years creates a substantial range of doubling times-from 17.96 (2009 to 2012) to 24.90 (2010 to 2011). Also, calculating a doubling time from a weighted average of the five-percentage-change figure (+3.4823) creates a slightly lower number, namely, 20.16 years (not shown in Table 1). This is because a constant rate of change creates exponential or increasing growth of a population over time as the base population grows ever larger. Hence, the percentage change was higher for the final three pairs of years; a weighted percentage change average creates this lower doubling time figure. However, if these same three pairings displayed smaller percentage change numbers than the first two years, the doubling time from a weighted average of percentage change would be larger than 20.4987.

According to a United Nations (2012) population report, the five-year (2005 to 2010) average percentage change in the Canadian population was +1.129 , and for the United States, it was +0.923 . Like the Amish population, these changes reflect population dynamics as expressed through natural change (births minus deaths) and net migration (in-migration minus outmigration). Assuming these rates of change are constant, the doubling time for Canada and the United States is much higher-61.74 years and 75.44 years, respectively_than the Amish doubling time.

Indeed, it is difficult to find a single country whose doubling time is lower than the Amish. Based on the same 5-year figures from the United Nations (2012), the most populous countries of the world, China and India, have doubling times of 158.60 and 51.84 years. A few countries in the Eastern and Western regions of Africa rival the Amish population increase, plus several of the small Arabian countries of the Persian Gulf. For example, Qatar's population increased 14.207\% annually (doubling time = 5.22 years) from 2005 to 2010, but this was due almost completely to the in-migration of workers who are citizens of other countries. On the other end of the doubling time spectrum is Japan, whose time it takes to double the population currently stands at 1,175 years, indicative of a very low percentage increase in its population $(+0.059)$. This is due to a combination of low fertility rates/small families and an aging population, which is not offset by net in-migration.

In general, the most developed countries — such as France (121.31 years) and the United Kingdom (119.85 years) — have high doubling times, while the poorest and least developed countries_-such as the South Sudan (16.01 years) and Liberia (18.49 years)—have low doubling times. This makes the Amish doubling time all the more remarkable, and is another way of 
demonstrating the extent to which their society and culture, existing in the midst of the advanced societies of Canada and the United States, is distinctive.

Table 2 breaks the data down further, suggesting some interesting patterns but also providing a strong cautionary note to basing population increase on only particular types of settlements. First off, for the 63 settlements where end-of-year statistics included reports for the number of households across all six years, a faster increase in the population and a lower doubling time can be found (Table 2). This may be due to a greater willingness of scribes from growing communities to report end-of-year statistics, or because settlements that are not growing or decreasing in size may not have someone interested in volunteering to count up and report end-of-year statistics, or even to submit reports on any topic to The Diary. If true, then the doubling time calculated from The Diary for this article is lower than what it really should be because the true proportion of settlements that are declining in population, or, alternatively, showing a net loss in number of households, is not known but is likely higher.

\section{Table 2: Doubling Time by Characteristics of Settlements}

\begin{tabular}{l|c|c|c} 
Characteristic & $\begin{array}{c}\text { Number of } \\
\text { settlements }\end{array}$ & $\begin{array}{c}\text { Percentage } \\
\text { change }\end{array}$ & $\begin{array}{c}\text { Doubling time } \\
\text { (in years) }\end{array}$ \\
\hline $\begin{array}{l}\text { Settlements reporting end-of-year } \\
\text { statistics for all years, 2009-14 }\end{array}$ & 62 & +3.9950 & 17.69 \\
\hline $\begin{array}{l}\text { Settlement size } \\
<30 \text { households }\end{array}$ & 154 & +6.9039 & 10.38 \\
30-99 households & 103 & +3.5044 & 20.12 \\
$\geq 100$ households & 39 & +2.6328 & 26.76 \\
\hline Age of settlement & 127 & & \\
founded in 21 & & +9.2194 & 7.86 \\
$\quad$ founded in 1980s or 1990s & 99 & +4.3027 & 16.45 \\
founded before 1980 & 70 & +2.0217 & 34.63
\end{tabular}

Table 2 also displays the difference in doubling time by the size of settlements. Size was based on the number of households for the earliest year that a scribe provided an end-of-year statistics report. Among settlements with fewer than 30 households, the doubling time was 10.38 years. Comparatively, medium sized settlements, ranging in size from 30 to 99 households, was slightly over 20 years, and for settlements with 100 or more households, the doubling time was 26.76 years. Certainly this shows that smaller settlements are growing faster; however, a more conservative explanation would be cautious about reaching this conclusion too quickly. The differences by settlement size demonstrate the need to calculate a doubling time based on a large number of settlements with a wide range of sizes or else the estimate is potentially biased. In 
particular, larger settlements present a more daunting task for the scribe who desires to submit an end-of-year statistics report that includes a count of households. ${ }^{8}$ As well, larger settlements are more likely to publish their own directories, listing all households and family members, negating the need to report end-of-year statistics to The Diary. Alternatively, their size gives them more weight in the statistical calculation of the doubling time, which may offset any bias introduced by the likelihood of The Diary publishing a disproportionate share of reports from scribes living in smaller settlements.

Related to size is the third set of numbers shown in Table 2, which is the doubling time based on the age of the settlement. For settlements founded in the twenty-first century, growth is very robust and the doubling time is quite low-7.86 years. Settlements founded sometime in the final two decades of the twentieth century are also growing, with a doubling time of nearly 16.5 years. In contrast, the older settlements (those founded before 1980) have a doubling time twice as high as those founded during the 1980s and 1990s, and nearly five times greater than settlements established in the twenty-first century. Even though these doubling time differences show that settlement age and doubling time co-vary, the results again demonstrate why it is important to include a large number of settlements across a wide range of founding dates in the calculations. Plus, larger settlements and older settlements are more likely to publish their own directories, reducing the need to submit a report to The Diary. Scribes from newer settlements may see an end-of-year statistics report as a way to spread the news about the locality and its attractiveness as a place to sustain Amish values and practices.

Using the 2010 base population of 250,771 from the county-based estimates by Donnermeyer, Anderson, and Cooksey (2013)_assuming the rate of increase remains constant and no unexpected schisms which result in new Anabaptist but non-Amish denominations-a doubling time of 20.5 years would mean a population of 501,542 by mid-year 2030, and slightly over a million Amish by mid-century. This level of growth will inevitably lead to other changes across all features of the Amish religious, social, cultural, and economic landscape.

\section{Limitations of the Research}

Previous doubling time estimates have not provided sufficient documentation for how the estimate was calculated. Furthermore, while the Young Center is clear that it is using the church district for its various population estimates, including population increase, the use of church districts is problematic because the number of households and individuals in districts can vary greatly. However, the attempt in this article to more scientifically develop an estimate of population increase / doubling time than previous attempts is not without its own limitations. For the sake of transparency and the avoidance of past claims-making that relies on limited empirical evidence, several potential weaknesses to the methodology used here should be pointed out.

The first potential source of error is the accuracy of the scribe. This is an important consideration since the estimate is based on consecutive year reports. Both under-counting and 
over-counting can lead to incorrect numbers for net change within individual settlements from one year to the next. However, this source of error is likely offset by using a large number of data-points, with the assumption that any errors in the actual household count by scribes are random.

A second limitation was already mentioned. Perhaps settlements with declining populations and/or net out-migration are less likely to be settlements where a scribe submits endof-year statistics. This might be especially true if the settlement is undergoing disagreement within or between church districts on the Ordnung (Luthy 2011). Even though about one-third of the settlements in this article for which The Diary reports included statistics for consecutive years showed no gain or loss in the number of households, perhaps the proportion is higher. This weakness is worth considering, as additional years of statistics is added to the database, with future refinements to the doubling time estimate developed for this and other publications.

A third limitation is the style of reporting by various scribes. Some scribes use the word "family" instead of "household." Some scribes state the number of households, while others give a total for the number of households or families, and then include a separate statement for the number of "single men" or "single women," and "widowers" and "widows" as well. It is not always easy to tell if these single person households were included in the statement for the total number of households, or if they should be added to that total number. Fortunately, less than 10 percent of the reports presented this kind of problem, and rarely was the number of singles/widows/widowers more than a couple of individuals. Hence, in nearly all but a few cases, this problem did not significantly alter the household size of an individual settlement, and certainly not the numerical value for the calculated doubling time. Nonetheless, each case of ambiguous reporting needs to be addressed in order to maintain a high level of accuracy.

The final limitation is the most important one, and the least answerable. How representative are the settlements for which end-of-year statistics are reported in The Diary? One related source of bias was described above: there may be less reporting of statistics for settlements that are declining or not growing. A second bias was also discussed: are there enough larger and older settlements in the set of consecutive year data-points to ensure the estimate is accurate across the spectrum of Amish settlements? One way to resolve this issue is to use available directories of larger and older settlements to see how much their populations have changed over the years, and compare this to the doubling time estimate established through this article's reported methodology. This suggests a future research project (perhaps a thesis or dissertation project of a budding demography graduate student), comparing estimated doubling times based on different sources of information.

\section{Summary and Conclusions}

This article attempts to document population increase through the use of the demographic concept of doubling time, with an estimate developed from end-of-year statistics on the number 
of households found in reports published in The Diary from scribes living in numerous settlements.

Demographic change in Amish society, especially population increase, will be an important factor underlying possible future changes in religious practices and social organization. A direct consequence of population gain is that it spurs the increase in new settlements and their geographic spread in North America (Donnermeyer and Luthy 2013), which in turn creates change in the fabric of Amish church, community and family life. More accurate statistics about the demographic dimensions of the Amish will also aid Anabaptist scholars to better understand these social and cultural changes.

There are practical applications for a doubling time estimate as well. Researchers interested in public health issues associated with the Amish — the most recent example being the measles outbreak in the large Greater Holmes County settlement of northeastern Ohio-require information that will help them map the possible spread of infectious diseases (Kisjes, Duintjer Tebbens, Wallace, Pallansch, Cochi, Wassilak, and Thompson 2014). Continuing work on road safety and visibility of horse-drawn conveyances benefits from a more precise knowledge of Amish population trends, and the continuing spread of settlements to new rural localities represents another example (Jepsen, Henwood, Donnermeyer, and Moyer 2011).

Now that the database for the doubling time estimate is established, it can be updated with each additional end-of-year statistics reports in The Diary. This will not only add more stability to the estimate, but also allow for more confidence in the results when breaking down the estimates by settlement size and settlement age, as well as other possible variations in Amish communities. Nonetheless, for the next several decades, if not the remainder of this century, demographic change will underlie many other changes in Amish society.

\section{Endnotes}

${ }^{1}$ For a description of the various Anabaptist and plain religious groups, including the Amish, in Canada and the United States, see Anderson's (2013) article "Who Are the Plain Anabaptists? What are the Plain Anabaptists?” in the inaugural issue of JAPAS.

${ }^{2}$ Johnson-Weiner's (2010) list does not include two other Amish settlements, both of which are part of the more progressive New Order Amish affiliation. These settlements are Lyndonville (founded in 1998) and Canastota (founded in 2006).

${ }^{3}$ For example, a 2010 Wall Street Journal news stories, citing a report from the Young Center, claims the growth rate is five percent a year. A constant five percent annual increase in population would create a doubling of the Amish population every 14.21 years. See "The Amish Population Boom,” Wall Street Journal, July 29, 2010 (blogs.wsj.com/economics/2010/07/29/ the-amish-population-boom/) 
${ }^{4}$ The actual five year calculation for this hypothetical example using a 20-year doubling time was 118.9 persons and for a doubling time of 23 years was 116.3 persons.

${ }^{5}$ A few scattered reports can also be found in the December and March issues of The Diary. Also, two other Amish periodicals, namely The Budget and Die Botschaft, include end-of-year statistics for many Amish settlements. Mostly, these are the same settlements and the identical reports.

${ }^{6}$ There are a few scribes who report on the actual number of people in their settlement, but too few to build a database adequate for the calculation of a doubling time for the Amish population.

${ }^{7}$ There are about 75 additional reports for settlements each year where the number of households is not provided but other information is given, such as births, deaths, number of school aged children, etc.

${ }^{8}$ In fact, a perusal of The Diary will reveal scribes from larger settlement submitting an end-ofyear statistics report but failing to provide a count of households, even though the number of babies born, the number of households moving in and moving out, the number of church districts, and other settlement details are described.

\section{References}

Anderson, Cory. 2013. "Who Are the Plain Anabaptists? What Are the Plain Anabaptists?” Journal of Amish and Plain Anabaptist Studies 1(1):26-71.

Anderson, Cory, and Joseph Donnermeyer. 2013. "Where Are the Plain Anabaptists?” Journal of Amish and Plain Anabaptist Studies 1(1):1-25.

Bogue, Donald. 1969. Principles of Demography. New York, NY: John Wiley and Sons.

Donnermeyer, Joseph, Cory Anderson, and Elizabeth Cooksey. 2013. “The Amish Population: County Estimates and Settlement Patterns.” Journal of Amish and Plain Anabaptist Studies 1(2):72-109.

Donnermeyer, Joseph, and Elizabeth Cooksey. 2010. "On the Recent Growth of New Amish Settlements.” Mennonite Quarterly Review 84(2):181-207.

Donnermeyer, Joseph, and David Luthy. 2013. “Amish Settlements across America: 2013.” Journal of Amish and Plain Anabaptist Studies 1(2):107-29.

Ericksen, Julia, Eugene Ericksen, John Hostetler, and Gertrude Huntington. 1980. "Fertility Patterns and Trends among the Old Order Amish.” Population Studies 33(2):255-76. 
Greska, Lawrence, and Jill Korbin. 2002. "Key Decisions in the Lives of the Old Order Amish: Joining the Church and Migrating to Another Settlement.” Mennonite Quarterly Review 76(4):373-98.

Hostetler, John. 1993. Amish Society [ $4^{\text {th }}$ ed.]. Baltimore, MD: Johns Hopkins University Press.

Hurst, Charles, and David McConnell. 2010. An Amish Paradox: Diversity and Change in the World's Largest Amish Community. Baltimore, MD: Johns Hopkins University Press.

Jepsen, S. Dee, Kathy Henwood, Joseph Donnermeyer, and Kay Moyer. 2011. "Identifying Culturally and Age-Appropriate Farm Safety Curricula for Anabaptist Youth.” Journal of Agricultural Safety and Health 18(1):57-67.

Johnson-Weiner, Karen. 2010. New York Amish: Life in the Plain Communities of the Empire State. Ithaca, NY: Cornell University Press.

Kisjes, Kasper, Radboud Duintjer Tebbens, Gregory Wallace, Mark Pallansch, Stephen Cochi, Steven Wassilak, and Kimberly Thompson. 2014. "Individual-Based Modeling of Potential Poliovirus Transmission in Connected Religious Communities in North Americans with Low Uptake of Vaccination.” Journal of Infectious Disease 210(supp 1):S424-S433.

Kraybill, Donald, Karen Johnson-Weiner, and Steven Nolt. 2013. The Amish. Baltimore, MD: Johns Hopkins University Press.

Kreps, George, Joseph Donnermeyer, and Marty Kreps. 1994. "The Changing Occupational Structure of Amish Males.” Rural Sociology 59(4):708-19.

Liepins, Ruth. 2000. "New Energies for an Old Idea: Reworking Approaches to 'Community' in Contemporary Rural Studies.” Journal of Rural Studies 16(1):23-35.

Luthy, David. 2011. Why Some Amish Communities Fail: Extinct Settlements, 1961-2011. Aylmer, ON: Pathway Publishers.

Luthy, David, and Joseph Donnermeyer. 2014. "Amish Settlements across America: As of October 31, 2013.” Family Life (January):20-25.

Meyers, Thomas. 1994. "The Old Order Amish: To Remain in the Faith or to Leave.” Mennonite Quarterly Review 68(3):378-95.

Meyers, Thomas, and Steven Nolt. 2005. An Amish Patchwork: Indiana's Old Orders in the Modern World. Bloomington, IN: Quarry Books.

Raber, Aden. 2015. The New American Almanac: Forty-Sixth Edition for the Year of Our Lord 2015. Baltic, OH: Aden Raber. 
Stevick, Richard. 2014. Growing Up Amish: The Teenage Years [2 ${ }^{\text {nd }}$ ed.]. Baltimore, MD: Johns Hopkins University Press.

United Nations, Department of Economic and Social Affairs. 2013. World Population Prospects: The 2012 Revision. New York, NY: United Nations, Population Division. Accessed March 12, 2015 (http://www.esa.un.org).

Warren, Roland. 1963. The Community in America. Chicago, IL: Rand McNally.

Wasao, Samson, and Joseph Donnermeyer. 1996. "An Analysis of Factors Related to Parity among the Amish in Northeast Ohio.” Population Studies 50:236-46.

Weinstein, Jay, and Vijayan Pillai. 2001. Demography: The Science of Population. Boston, MA: Allyn and Bacon.

Wengerd, Marvin (ed.). 2015. Ohio Amish Directory: Holmes County and Vicinity. Walnut Creek, OH: Carlisle Press.

Young Center for Anabaptists and Pietist Studies. 2014. Amish Population Profile 2014. Elizabethtown, PA: Elizabethtown College. Accessed March 15, 2015 (http://www2.etown.edu/amishstudies/Population_Profile_2014.asp).

Zimmerman Umble, Diane, and David Weaver-Zercher (eds.). 2008. The Amish and the Media. Baltimore, MD: Johns Hopkins University Press. 